\title{
Arquitetos Peregrinos \& Modernidades em São Luís e Alcântara -MA
}

\author{
Pilgrim Architects \& Modernities in São Luís and Alcântara -MA
}

\author{
(D) Grete Soares Pflueger \\ Universidade Estadual do Maranhão, São Luís, Maranhão, Brasil \\ gretepfl@gmail.com
}

Resumo

Este artigo busca documentar e resgatar a presença dos arquitetos e arquitetas peregrinos na cidade de São Luis e Alcântara -Ma, que contribuíram para a disseminação e circulação de ideias modernas com consultorias, planos e projetos arquitetônicos e urbanos para o Estado do Maranhão no século XX. Destacamos o arquiteto Raphael Galvão que projetou a sede dos correios, o urbanista Otacílio Saboya Ribeiro, que foi prefeito e autor de projeto de embelezamento da capital em 1936, seguido dos consultores da Unesco: o arquiteto português Viana de Lima e Michel Parent entre 1950-60, com ideias importantes ao processo de proteção do conjunto arquitetônico colonial e para dinamização da cidade face ao isolamento econômico do Estado, além dos arquitetos Pedro e Dora Alcântara, que moraram em São Luís e Alcântara na década de 1960 e elaboraram um plano de preservação para a cidade. Destacamos ainda, no âmbito de projetos, a dupla Acácio Gil Borsoi e Janete Costa com projetos de reabilitação do Palácio e Teatro, residências e hospital, e a obra marcante do arquiteto Luís Filgueiras Lima, o Lelé, com o projeto do Hospital Sarah, e por fim o projeto de Niemeyer para a praça Maria Aragão. Os arquitetos peregrinos disseminaram ideias que circulavam no Brasil moderno possibilitaram a chegada das modernidades na ilha. Catalogar e divulgar estas obras é uma forma de preservar o conjunto arquitetônico do século XX.

Palavras-chave: Arquitetos peregrinos. arquitetura Moderna no Maranhão. planos urbanos São Luís e Alcântara.

\section{Abstract}

This article seeks to document and rescue the presence of pilgrim architects in the cities of São Luis and Alcântara -Ma, who contributed to the dissemination and circulation of modern ideas through consultancy, plans and architectural and urban projects for the State of Maranhão in the 20th century. We highlight the architect Raphael Galvão, who designed the post office, the urbanist Otacilio Sabóya 
Ribeiro, who was mayor and author of the capital's embellishment project in 1936, followed by Unesco consultants: the Portuguese architect Viana de lima and Michel Parent between 1950-60, with important ideas for the process of protecting the colonial architectural ensemble and for boosting the city in the face of the state's economic isolation, in addition to the architects Pedro and Dora Alcântara, who lived in São Luís and Alcântara in the 1960s and developed a preservation plan for the city. We also highlight, in the scope of projects, the duo Acácio Gil Borsoi and Janete Costa with projects for the rehabilitation of the Palace and Theater, residences and hospital, and the remarkable Works of the architect Luís Filgueiras Lima, - Lelé with the Sarah Hospital project, and also Niemeyer's project for Maria Aragão square. The pilgrim architects disseminated ideas that circulated modern Brazil made it possible for modernities to arrive on the island. To catalog and disseminate these works is a way to preserve the architectural ensemble of the 20th century.

Keywords: Pilgrim architects. modern architecture in Maranhão. São Luís and Alcântara's urban plans.

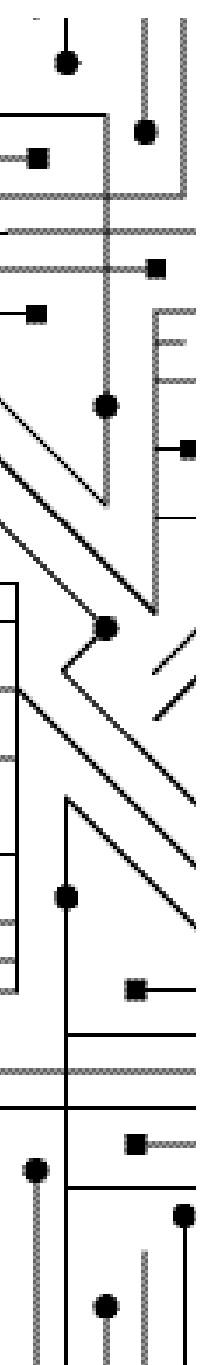




\section{Introdução}

Documentar a arquitetura e o urbanismo do século $X X$ tem sido um grande desafio aos pesquisadores das redes de pesquisa e universidades da Amazônia, na busca pelos arquivos, acervos, autorias e plantas originais, registros de ideias e relatórios, sobretudo pela concentração destas informações nos grandes acervos da capital federal e pela falta de arquivos locais organizados. A circulação de ideias e de profissionais pelo Brasil do século XX difundiu novas perspectivas, novas linguagens e possibilitou a chegada de novos planos e projetos. Esse é o desafio deste artigo: mapear, conhecer esses arquitetos que vieram para o Nordeste e contribuíram para a expansão urbana das cidades e para a chegada da arquitetura moderna.

No Maranhão, o reconhecimento pela Unesco e inscrição da capital São Luís como patrimônio da humanidade em 1997, fez convergir os esforços de pesquisa e documentação para o acervo do século XVIII e XIX, protegidos pelas leis de tombamento estadual, federal e municipal, e com urgência em sua preservação, deixando o acervo do século XX para documentação e proteção posterior. A ideia de preservar o acervo do século XX no pais é recente e no Maranhão, mais recente ainda. Hoje há uma maior consciência da necessidade de preservar o acervo do século $X X$, tanto nas ações de órgãos federais, estaduais e municipais como estimulado pela dinâmica atuação das redes de pesquisa como Docomomo e Amazônia moderna que incentivam as pesquisas e divulgam o acervo do século XX. É importante lembrar que a cidade tem diferentes temporalidades e todas elas são fundamentais na preservação da memória do lugar.

Calvino (1990) no livro "Cidades invisíveis" nos fala das cidades e dos símbolos e nos lembra "que a cidade é feita das relações entre as medidas de seu espaço e a os acontecimentos do passado, que ela não conta seu passado, ela o contém como as linhas da mão, escrito nos ângulos das ruas, nas grades das janelas". Afirma ainda a que a cidade é feita das trocas e das memórias passadas e presentes, dos discursos que a descrevem, metáforas adequadas ao desafio de compreender a troca do homem e da cidade, também citadas pelo poeta maranhense Ferreira Gullar 
(2010) em seu Poema sujo: "o homem está na cidade como uma coisa está em outra e a cidade está no homem que está em outra cidade". Nos lembrando do quanto é importante documentar as trocas, as redes de pessoas, as ideias e movimentos que fazem uma cidade crescer e se expandir e que motivam as construções, edifícios e os conjuntos arquitetônicos e urbanos e sobretudo que essa troca acontece com as relações humanas, as trocas de conhecimentos ideias e projetos que circulam e constituem uma rede local, nacional e internacional conectando pessoas, ideias e lugares.

Este artigo busca catalogar, conhecer e iluminar a presença de arquitetos nômades, peregrinos e migrantes, como parte integrante do diretório de pesquisa do CNPQ intitulado "ideários urbanos e linguagens arquitetônicas de São Luís- MA no século XX" ,inspirado pela necessidade de compreender as trocas, os profissionais e as redes de disseminação da arquitetura moderna, tomando como base teórica o capítulo do livro de Hugo Segawa, Arquitetura do Brasil (1999), que fala de arquitetos peregrinos, nômades e migrantes.

Segawa (1999) destaca dois fatores significativos para a "disseminação dos valores da arquitetura moderna no País: a criação de escolas de arquitetura e o deslocamento de profissionais de uma região para outra, como fator decisivo para afirmação da linguagem moderna no Brasil". No caso de São Luís, somente em 1994 foi criado o curso de Arquitetura e Urbanismo da Universidade Estadual.

Partindo dessa abordagem e compreendendo o isolamento econômico do Estado do Maranhão, no início do século XX, observamos na pesquisa que a chegada da arquitetura moderna em São Luís teve sobretudo motivações externas, com os projetos para a construção das sedes de instituições públicas federais e com a vinda de arquitetos nômades e peregrinos e migrantes que moraram no Estado, projetaram, idealizaram a cidade ou vieram em missões como observadores internacionais.

As ideias destes profissionais circularam e deixaram fortes influências na capital e interior do estado, como na cidade de Alcântara, nas ações de preservação do patrimônio histórico, na expansão urbana e da dinâmica urbanas. 
A metodologia desta pesquisa foi feita com a coleta de dados e relatórios sobre os arquitetos que vieram para São Luís, em diferentes acervos públicos estaduais e federais e com a pesquisa de campo de catalogação de obras em duas categorias: projetos arquitetônicos e planos e relatórios urbanos, seguida da construção de uma timeline, uma cronologia da presença destes profissionais nacionais e internacionais, que formaram uma rede de ideias e contribuíram para a formação da consciência da preservação da cidade e para a mudança da linguagem arquitetônica e inserção das modernidades e suas influências na contemporaneidade. Ressaltamos a presença feminina na arquitetura em São Luís, nas duplas de profissionais Pedro e Dora Alcântara e Acácio Borsoi e Janete Costa, iluminando a presença feminina no panorama da produção arquitetônica teórica, projetual e urbana no Estado.

Destacamos por ordem cronológica um dos primeiros projetos realizados na capital, do arquiteto Rafael Galvão para a sede dos correios em 1933; o plano de 1936 do urbanista Otacílio Saboya Ribeiro, que foi prefeito e autor de projeto de embelezamento da capital, seguido dos consultores da Unesco entre os anos 196773 , o arquiteto francês Michel Parent e o português Viana de Lima e Raul Pastana , com ideias importantes ao processo de proteção do conjunto arquitetônico colonial e para dinamização da cidade de São Luís e Alcântara, face ao isolamento econômico do Estado, na perspectiva do turismo cultural, além dos arquitetos Pedro e Dora Alcântara , que moraram em São Luís e Alcântara na década de 1960 e elaboraram um plano de preservação para a cidade. Em 1977, destacamos o plano do arquiteto Wit Olaf Prochnik, convidado pelo visionário prefeito Haroldo Tavares que possibilitou a expansão urbana de São Luís e em 1979, a ilustre visita do arquiteto Lúcio Costa em São Luís e suas ideias não executadas para um novo polo urbano. Ainda em 1979 tivemos o plano do americano John Gisiger para renovação urbana para o centro histórico de São Luís. Destacamos ainda, no âmbito de projetos arquitetônicos, a dupla Acácio Gil Borsoi e Janete costa com projetos de reabilitação do Palácio dos Leões e teatro, residências e hospital, e a obra marcante do arquiteto Luís Filgueiras lima -Lelé com o projeto do hospital Sarah de São Luis, e por fim o projeto icônico de Niemeyer para a praça Maria Aragão. 
de novas sedes nas principais capitais brasileiras.

Os edifícios eram estrategicamente localizados em esquina em áreas nobres dos centros renovando a linguagem arquitetônica. Observamos nas regiões norte e nordeste do país várias sedes com projetos similares e, no caso de São Luís, esse projeto reforça a tese de que foram os projetos institucionais que disseminaram a arquitetura moderna na ilha.

O projeto da sede de São Luís foi arrojado, foi construído com a demolição de dois sobrados coloniais que ocupavam a esquina na Praça João Lisboa com a rua do Sol, ao lado do tradicional teatro Arthur Azevedo, exemplar da arquitetura neoclássica, e da tradicional igreja e convento do Carmo, no coração do centro histórico de São Luís. A nova linguagem arquitetônica moderna, com linhas do art déco causou impacto na cidade, com fachada geométrica, linhas horizontais e verticais. A obra foi executada entre 1931 e 1935 e o imóvel encontra-se hoje em bom estado de conservação, sofreu várias reformas e a agência funciona normalmente. Não há registros de mais projetos do autor na cidade, portanto deve ter sido enviado um projeto para a cidade dentro das ações federais de expansão dos correios.

Figura 2- Sede dos Correios em São Luís.

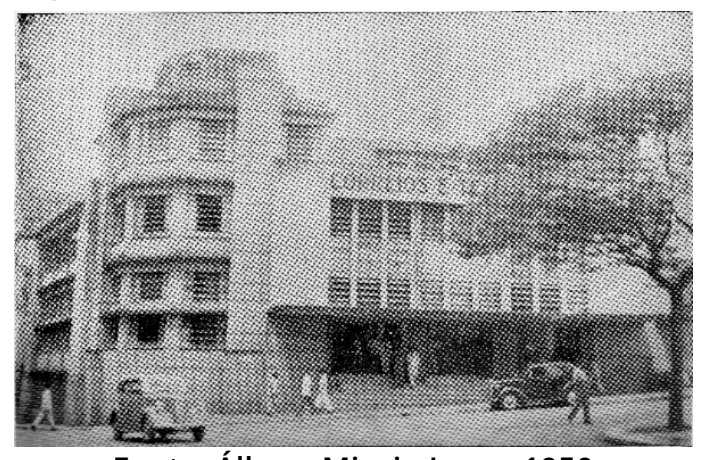

Fonte: Álbum Miecio Jorge, 1950
Figura 3- Planta de São Luís de 1950.

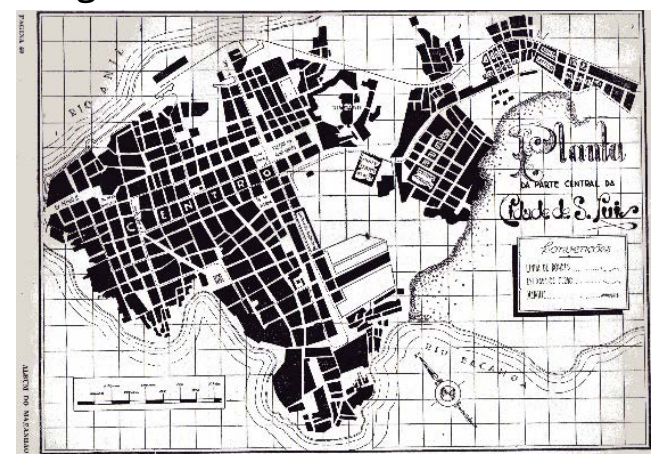

Fonte: Álbum Miecio Jorge, 1950

A renovação urbana de São Luís, no contexto da "Era Vargas" estava só começando, e logo chegaria a cidade em 1936 o jovem urbanista José Otacílio Saboya Ribeiro (1899-1967), que formulou um plano para transformar a velha capital colonial em uma cidade de feição moderna. Otacílio foi prefeito de São Luís e criou uma comissão para elaborar o plano da cidade, integrada por figuras representativas 
da sociedade para a remodelação da capital, com o plano de demolir para renovar as ruas estreitas e becos por largas avenidas, mas não foi bem entendido e teve a recusa da Associação Comercial, que inviabilizou seu plano economicamente assim como as suas ideias avançadas. Otacílio permaneceu apenas um ano no Maranhão e seu plano foi publicado no diário oficial, mas ficou restrito as ideias. Otacílio deixou a Prefeitura em 1937 e ingressou como professor na cadeira de urbanismo da Faculdade Nacional de Arquitetura da Universidade do Brasil, onde atuou na coordenação do curso de Urbanismo. Em recente visita ao Prourb na UFRJ, tivemos informação que parte do acervo de Otacílio foi doado pela família à UFRJ.

No governo do interventor Paulo Ramos no Maranhão, as renovações urbanas incorporaram as ideias de Sabóya Ribeiro e foram executadas em parte, pelo sucessor, o Prefeito Pedro Neiva de Santana, que administrou São Luis entre 1937-1945. A permanência do urbanista foi efêmera, mas suas ideias influenciaram a abertura de avenidas e a expansão da cidade.

8

Figura 4 - Plano de Recuperação de Alcântara

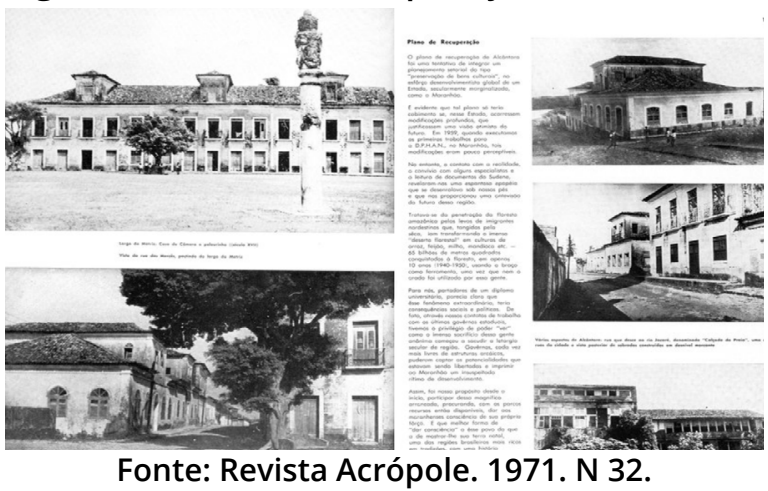

Fonte: Revista Acrópole. 1971. N 32.
Figura 5 - arquitetos Dora e Pedro.

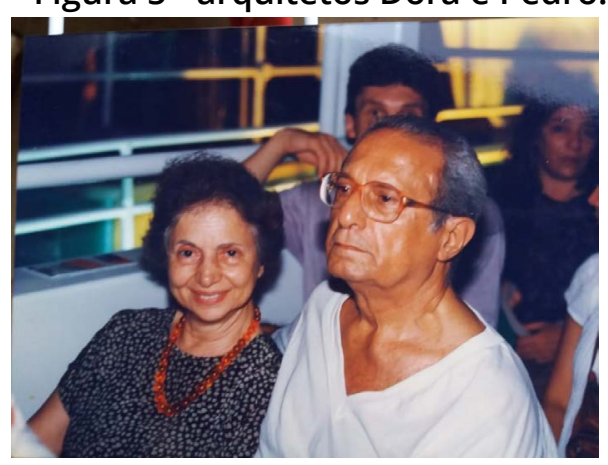

Fonte: acervo Dora Alcântara, 2020.

Posteriormente, nos anos de 1957-60, O casal de arquitetos ligados ao Patrimônio Nacional IPHAN - Rio de Janeiro, Antônio Pedro Gomes de Alcântara e a arquiteta Dora Monteiro e Silva de Alcântara (fig. 5) moraram em São Luís e Alcântara. Eles foram figuras importantes na construção do dossiê de tombamento de São Luís pela Unesco e sempre contribuíram para questão da preservação do patrimônio no estado do Maranhão. A pesquisa de Pedro foi pioneira nos estudos da formação histórica e urbana da cidade de Alcântara e o levantamento de azulejaria 
em São Luís e Alcântara realizado pela Dora e publicado em livro é o mais importante trabalho na área no Estado e no Brasil. As pesquisas de Pedro e Dora foram a base teórica para pesquisa de dissertação de mestrado intitulada: "De Tapuitapera a Villa D'Alcântara composição urbana e arquitetônica de Alcântara no Maranhão" (Pflueger 2002) defendida na Universidade Federal de Pernambuco, sobre a formação de Alcântara e tese de doutorado intitulada: "Rede e Ruínas: apogeu e declínio de uma cidade o caso de Alcântara no Maranhão" (Pflueger ,2011) defendido na UFRJ , e tem sido referência para todos os pesquisadores do Estado.

Eles produziram o relatório intitulado "Plano de recuperação de Alcântara", (fig.4) que foi publicado pela revista Acrópole No 32 -383, de abril de 1971 e hoje está disponível on line . O Plano foi premiado, reconhecido em sua relevância e de acordo com os autores ele foi: "uma tentativa de integrar um planejamento setorial do tipo preservação de bens culturais no esforço do desenvolvimentista global de um estado secularmente marginalizado como o Maranhão". (Plano ,1971). O plano iniciava pela descrição da estrutura da cidade delimitando seus marcos originais, igrejas e conventos e sobrados e apresentava uma lista de recomendações que foi entregue ao governador da época Dr.Matos Carvalho para transformar a cidade, dinamizar o turismo, estimulando as atividades econômicas da pesca e do artesanato como estratégias a preservação do conjunto tombado da cidade de Alcântara. O plano indicava a necessidade da uma pesquisa bibliográfica aprofundada e apresentava um o roteiro de uma exposição itinerante sobre a formação da cidade, muito interessante que ainda hoje seria estratégica para a educação patrimonial.

Ainda entre os anos 1970 e 1977, outro importante urbanista peregrino que esteve em São Luís a convite da municipalidade, na gestão do prefeito Eng. Haroldo Olympio Lisboa Tavares foi o arquiteto urbanista carioca Wit-Olaf Prochnik, que tinha uma empresa de Arquitetura e Planejamento urbano, com sede no Rio de janeiro e atuação em diversas capitais como São Paulo, Recife, Belém, Manaus e Brasília. Olaf elaborou o plano diretor de São Luís (fig. 6 e 7) com as diretrizes para a expansão 
urbana, viária e um novo zoneamento da cidade e projetou um prédio para o campus da Universidade Federal do Maranhão.

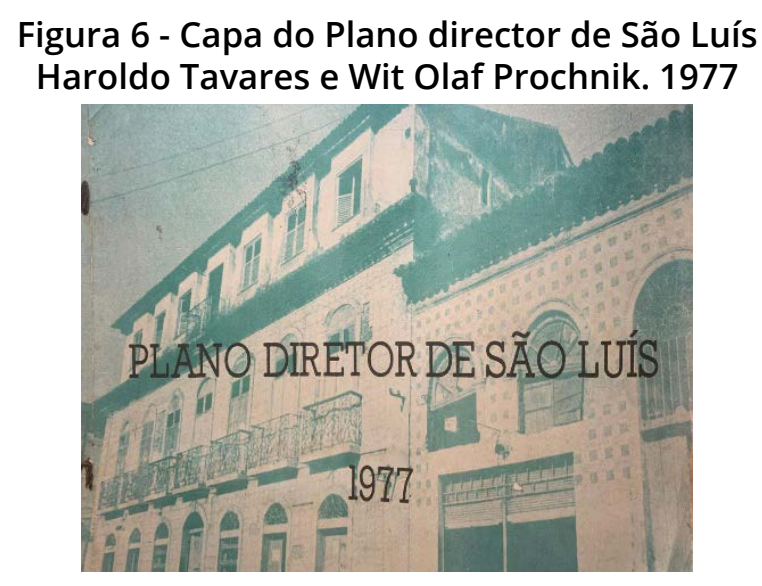

Fonte: plano diretor de São Luís, Maranhão, 1977. acervo Biblioteca CAU UEMA
Figura 7- Mapa do Plano director de São Luís Haroldo Tavares e Wit Olaf Prochnik.

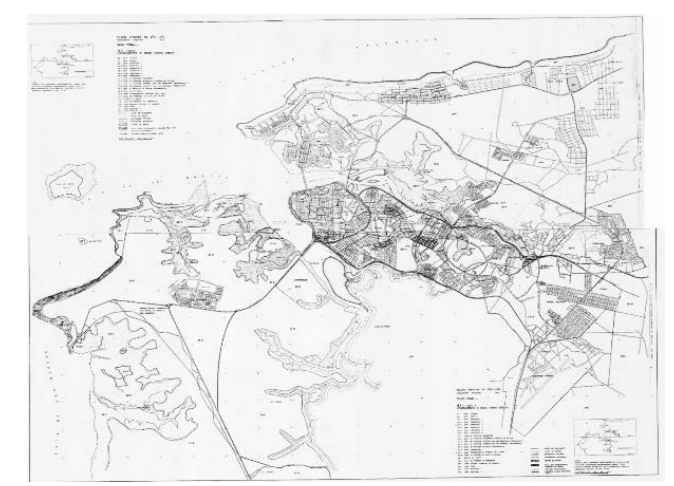

Fonte: plano diretor de São Luís, Maranhão, 1977. acervo Biblioteca CAU UEMA

Ainda entre os anos 1970 e 1977, outro importante urbanista peregrino que esteve em São Luís a convite da municipalidade, na gestão do prefeito Eng. Haroldo Olympio Lisboa Tavares foi o arquiteto urbanista carioca Wit-Olaf Prochnik, que tinha uma empresa de Arquitetura e Planejamento urbano, com sede no Rio de janeiro e atuação em diversas capitais como São Paulo, Recife, Belém, Manaus e Brasília. Olaf elaborou o plano diretor de São Luís (fig. 6 e 7) com as diretrizes para a expansão urbana, viária e um novo zoneamento da cidade e projetou um prédio para o campus da Universidade Federal do Maranhão.

A iniciativa urbana inovadora do prefeito Haroldo Tavares planejada pelo arquiteto Wit Olaf, tinha por objetivo organizar a estrutura urbana. Como um visionário da expansão, ele pensava em dar condições a capital a São Luís de receber o impacto dos grandes investimentos, com desenvolvimento urbano, equilibrado e racional, na sua gestão que foi criado um Anel Viário, estrutura viária que circunda o centro histórico possibilitando a articulação de novas canais de tráfego e circulação na cidade, normatizando ,interligando e zoneando-as áreas de expansão.

Entre os anos de 1960 e 1973 a UNESCO convidou arquitetos e urbanistas e realizou várias missões técnicas que ocorreram em diferentes cidades no Brasil e 
tinham o objetivo de difundir o turismo cultural dentro do programa de assistência para países em desenvolvimento. O Iphan documentou no livro sobre as Missões da Unesco (2008) a visita técnica do arquiteto Francês Michel Parent (fig.10) em várias cidades brasileira incluindo São Luís e Alcântara, "num contexto de ênfase da relação entre turismo, o desenvolvimento econômico, a preservação e valorização do patrimônio cultural e na busca de cooperação entre organismos voltados para a preservação do patrimônio cultural". Em São Luís, Parent "teve importância fundamental na revitalização e proteção do centro histórico da capital maranhense, assim como influenciou fortemente os trabalhos desenvolvidos pelo arquiteto português Viana de Lima, que viria depois a São Luís e Alcântara”. (As Missões, 2008)

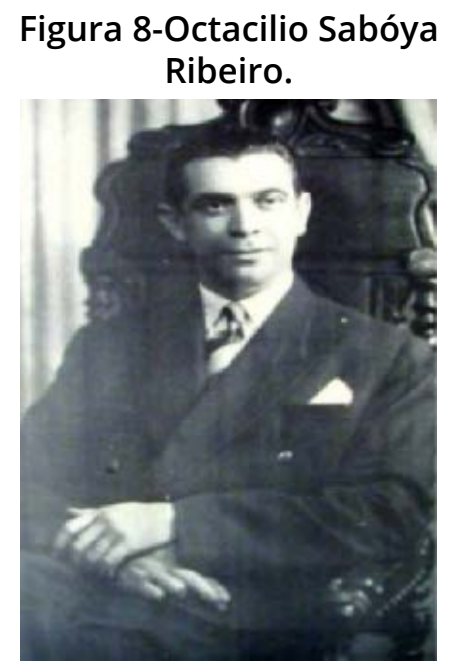

Fonte: Acervo biblioteca DAU.
Figura 9- Viana de Lima.

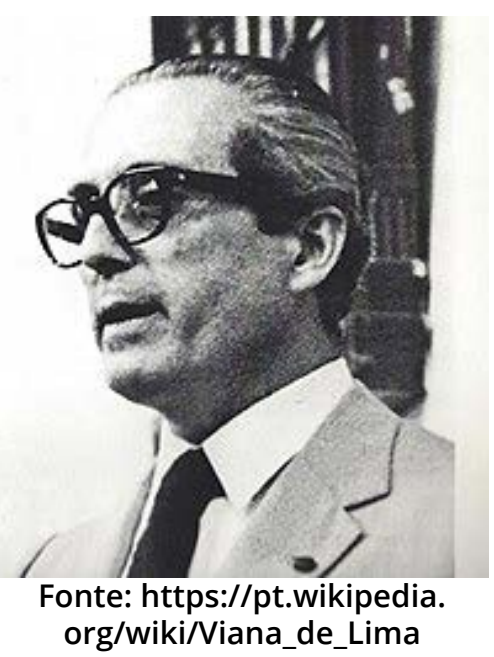

Figura 10- Michel Parent.

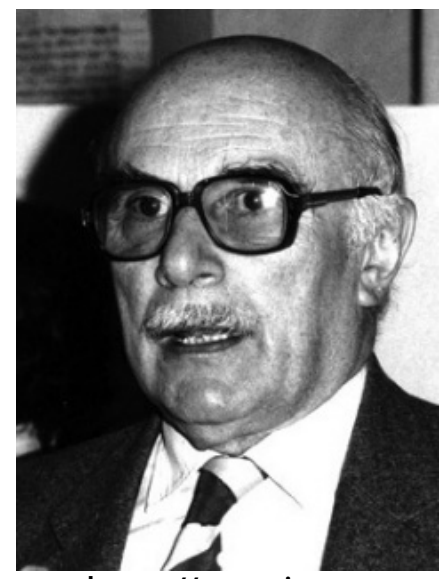

Fonte: https://www.icomos.org/ secretariat/in_memoriam/michel_ parent_en.ht

Parent (As missões, 2008) destacou algumas cidades como "Olinda, "uma das joias do Brasil”; São Luís, “a cidade dos pequenos palácios" e Alcântara, uma cidade entre arruinada e preservada, "a Pompéia ou a Herculano brasileira". As recomendações do consultor permanecem atuais e refletem o pensamento da importância da sustentabilidade urbana, social e econômica na preservação dos centros históricos. Outra missão importante foi do arquiteto Português Alfredo Evangelista Viana de Lima que elaborou um panorama do centro histórico, que resultou no "Rapport et propositions pour la conservation, recuperation et expansion" de São Luís/Maranhão. 
Ele apontou diretrizes e proposições para a expansão orientada da cidade, indicando elementos de planejamento urbano para a capital maranhense, como o Zoneamento. Viana de Lima tambem esteve em Alcântara e suas orientações foram fundamentais a preservação da cidade diante da fragilidade de seu conjunto urbano em ruínas na década de 1970. Destacamos ainda os estudos e relatórios sobre Alcântara do consultor da Unesco Raul Pastrana, que consta no acervo da coordenadoria de Patrimônio Histórico Estadual do Maranhão, enviada de Paris em setembro de 1984 aos representantes do patrimônio histórico estadual de São Luis, Phelipe Andrés e Ronald Silva, onde ele destaca que: "Revitalizar un centro histórico es uma actvidade global que no puede omitir de la consideracion de ninguno de los aspectos: sociales, culturales, econômicos, políticos y físicos y sus s articulaciones recíprocas, que hazen que um conjunto de edifícios sea una ciudad". (Pastrana 1984)

Finalizando as ideias e os plano urbanos ainda destacamos em 1979 a visita ilustre de Lucio Costa em São Luís e suas ideias para um novo polo urbano, plano pouco conhecido e não executado, cujas ideias ficaram no papel, seguido do plano do arquiteto americano John Gisiger, que formulou uma importante proposta de revitalização do bairro da grande, centro de São Luís com inserção da comunidade no processo e de estímulo à habitação no centro. Este projeto ainda é uma grande referência na preservação do patrimônio do Estado.

Os arquitetos engenheiros e urbanistas nômades e peregrinos e migrantes produziram importantes relatórios recomendando o tombamento das cidades, a preservação do conjunto arquitetônico e de práticas culturais e a delimitação das áreas históricas, apontando a necessidade de um plano geral de urbanismo, valorizando as praças e o conjunto de sobrados azulejados, propondo para São Luís a criação de universidades dentro do centro histórico, (que foi realizado muito posteriormente , tendo como exemplo a sede do curso de Arquitetura e Urbanismo da UEMA), para dinamização da área e incentivo ao turismo, e para Alcântara a proteção e estabilização das ruínas e incentivo ao turismo cultural. 
Havia no poder público uma enorme preocupação com a preservação do centro e a expansão da cidade. Era preciso conciliar o antigo e o moderno na capital e aplicar as recomendações e ideias contidas nos planos e relatórios como norteadores das políticas públicas de preservação e expansão urbana em São Luís e também de Alcântara. Como decorrência dos relatórios e das ideias dos consultores e diante da importância de proteger e dinamizar o conjunto urbano e arquitetônico, em 1974 o Centro Histórico de São Luís foi tombado pelo IPHAN; em 1986, pelo governo Estadual, e em 1997 a UNESCO inscreveu o Centro Histórico de São Luís na lista de patrimônio mundial. Alcântara já tinha seu tombamento pelo IPHAN desde o ano de 1948, mas estava ameaçada pela fragilidade do conjunto urbano em ruínas e pelo isolamento econômico. Os relatórios alertaram e apontaram estratégias para a preservação do conjunto.

Dentre as categorias estudadas no artigo, na cronologia proposta retomamos as obras e projetos de arquitetos com destaque no conjunto arquitetônico de São Luís. Bruand (2016) quando trata da arquitetura do Nordeste e cita a obra pioneira modernista de Luís Nunes, afirma que a renovação da arquitetura do Nordeste recebeu dois grandes talentos: Acácio Gil Borsoi, do Rio de janeiro e Delfim Amorim. Borsoi projetou no Maranhão em 1982 o hospital do IPEM, hoje conhecido como Carlos Macieira. Importante obra moderna e brutalista em concreto com elementos vazados e brises na fachada, é uma das obras de referência da capital maranhense. Posteriormente entre os anos de 1994-97, os arquitetos Acácio Gil Borsoi e Janete Costa, trabalharam em grandes projetos de reabilitação e restauro em importantes monumentos da cidade como teatro Arthur Azevedo e Palácio dos Leões, sede do governo do estado.

Em 1988, outro importante projeto hospitalar foi construído na capital, com projeto do premiado arquiteto João Filgueiras Lima- Lelé - Projeto do hospital referência da rede Sarah Kubistchek. Em 1991, a cidade tambem recebe um projeto do prêmio Pritzker de arquitetura, Oscar Niemeyer, em homenagem a médica Maria Aragão. Niemeyer idealizou a pedido da prefeitura o projeto arquitetônico para o memorial, construído em 1991, em forma de pomba, que abriga auditório, lojas, anfiteatro e 
palco para eventos públicos. Situado na Avenida Beira Mar, área de entorno do centro histórico, um marco da arquitetura contemporânea na cidade.

\begin{abstract}
Figura 11 - - hospital Carlos Macieira, em São Luís projeto de Borsoi.
\end{abstract}

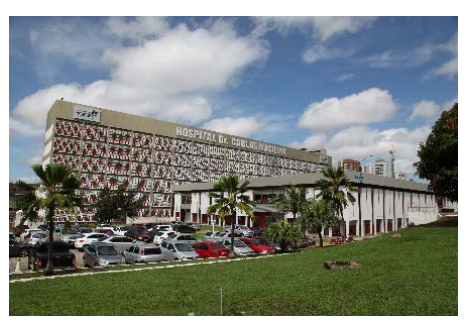

Fonte: acervo pesquisa UEMA.
Figura 12 - Teatro Arthur azevedo, São Luis, projeto Borsoi e Janete Costa.

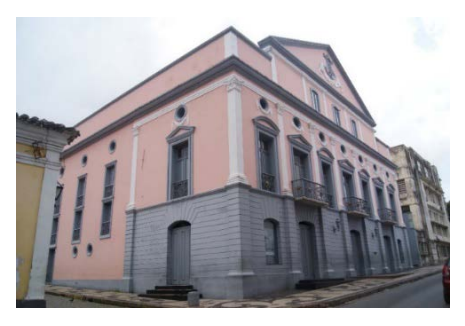

Fonte: acervo pesquisa UEMA.
Figura 13 - Acacio Gil Borsoi.

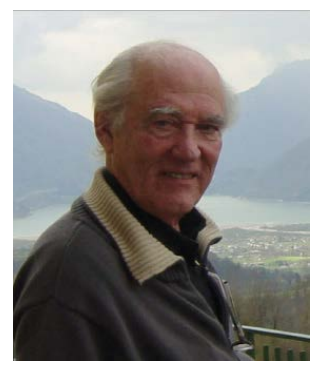

Fonte: acervo pesquisa UEMA
Figura 14- Janete costa.

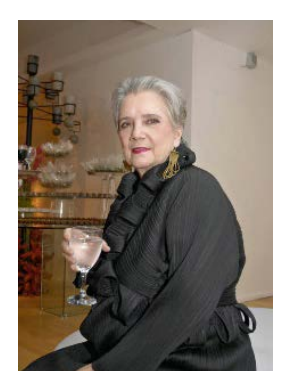

Fonte: casaclaudia. abril.com.br

Todos os arquitetos e urbanistas que pensaram ou projetaram para São Luís e Alcântara, durante o século XX, formaram uma rede de profissionais conectados com a melhoria das cidades, gerando um grande banco de ideias que contribuíram para o reconhecimento da cidade como patrimônio da humanidade e para a expansão urbana. Todo esse material produzido e construído constitui a memória da cidade no século XX. Muitas ideias e projetos podem ainda inspirar e nortear o planejamento urbano contemporâneo.

\section{Conclusão}

O artigo buscou visibilizar, catalogar e refletir sobre a presença de arquitetos e arquitetas peregrinos, nômades migrantes e consultores que contribuíram com suas ideias, projetos e planos urbanos para transformar, preservar e pensar a expansão urbana de São luís e Alcântara. Este acervo da arquitetura e urbanismo do século XX têm sido ainda pouco pesquisados em São Luís e hoje na perspectiva das redes de pesquisa e documentação da arquitetura moderna na Amazônia buscamos divulgar essas pesquisas. 
Calvino (1999) nos lembra "que jamais se deve confundir uma cidade com o discurso que a descreve. Contudo, existe uma ligação entre eles". As narrativas da cidade, das ideias vigentes a cada temporalidade são expressões humanas das tecnologias, dos ideários e das possibilidades de cada tempo. Quando analisados hoje, os planos urbanos e relatórios dos consultores, parecem atuais e os projetos ainda dialogam com nossa modernidade. Concluímos que para entender as modernidades em São Luís do Maranhão foi necessário compreender todo o conjunto de ideais para a renovação urbana contida nos planos, somados as recomendações dos consultores internacionais e a apropriação da comunidade com as resistências e as assimilações dos novos edificios, num permanente diálogo entre o passado e o presente, entre a arquitetura e o urbanismo, entre as ideias, as práticas, os saberes e fazeres que compõe a cidade contemporânea.

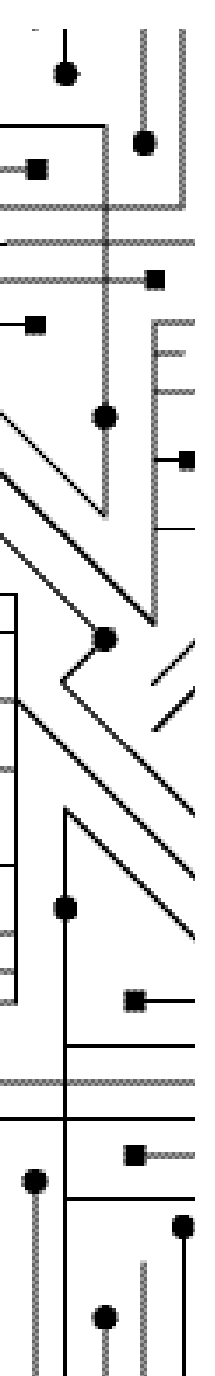




\section{REFERÊNCIAS}

AS MISSÕES da Unesco no Brasil: Michel Parent. [Tradução de Rejane Maria Lobo Vieira]; organização e texto de Claudia Feierabend Baeta Leal. - Rio de Janeiro: IPHAN, COPEDOC, 2008.

BRUAND, Yves. Arquitetura Contemporânea no Brasil. Ed. Perspectiva, São Paulo. 1991

BASTOS, Maria Alice Junqueira e Ruth Verde Zein. Arquitetura após 1950. -São Paulo: Perspectiva, 2011

CAVALCANTI, L. A. P. Quando o Brasil era moderno: Guia de arquitetura brasileira, 1928-1960. 2. Ed. Rio de Janeiro: Aeroplano, 2001. V. 1. 467 p.

CENTRO HISTÓRICO DE SÃO LUÍS-MARANHÃO: Patrimônio Mundial. Coord.Luiz Phelipe Andrés. São Paulo: Audichroma. 1998.

CALVINO, Ítalo. Cidades invisíveis. São Paulo, Companhia das letras, 1990

16

GULLAR, Ferreira. Toda poesia. Rio de Janeiro, Ed Jose Olympio 2010.o

JORGE, Miécio. Álbum do Maranhão, 1950. Maranhão, 1950.

MARANHÃO. Plano Diretor de São Luís 1977. São Luís: SIOGE, 1977.

LIMA, Alfredo Evangelista Viana de. Estado do Maranhão - São Luís. Relatório e propostas para a conservação, recuperação e expansão. Porto, Portugal: 1973; Estado do Maranhão - Alcântara. Relatório e propostas para a conservação, recuperação e expansão. Porto, Portugal: 1973

MEIRELES, Mário. História do Comércio no Maranhão. Vol.: III São Luís: Lithograf.1992

MOREIRA, Fernando Diniz (org.). Arquitetura moderna no Norte e Nordeste do Brasil: universalidade e diversidade. 1 ed. Recife: FASA, 2007. 392p.

Plano de recuperação de Alcântara. 1971. Pedro e Dora Alcântara. Revista acrópole no abril de 1971 № 32. Disponível I em http://www.acropole.fau.usp.br/edicao/383/11. Acesso 23/10/2020 
PFLUEGER G e LOPES, Jose Antônio. Arquitetura do século XX in São Luís - Ilha do Maranhão e Alcântara: Guia de Arquitetura e Paisagem. 1 ed. (bilíngue). Sevilla: Dirección General de Arquitectura y Vivienda, 2008. 448 p.

PFLUEGER, G. De Tapuitapera a Villa D'Alcântara composição urbana e arquitetônica de Alcântara no Maranhão. UFPE .2002 https://repositorio.ufpe.br/ handle/123456789/3377.

PFLUEGER, G. Rede e Ruínas: apogeu e declínio de uma cidade o caso de Alcântara no Maranhão". FAU- PROURB -UFRJ,2011http://www.prourb.fau.ufrj.br/grete-soarespflueger/

SEGAWA, Hugo. Arquiteturas no Brasil: 1900-1990. São Paulo: EDUSP, 1999.

\section{Publisher}

Universidade Federal de Goiás. Faculdade/Instituto/Escola. Programa de Pós-graduação Projeto e Cidade. Publicação no Portal de Periódicos UFG.

As ideias expressadas neste artigo são de responsabilidade de seus autores, não representando, necessariamente, a opinião dos editores ou da universidade.

RECEBIDO EM: 23/10/2020

APROVADO EM: 28/10/2020

PUBLICADO EM: 24/11/2020 